\title{
Improvement in pig growth and feed conversion due to knowledge transfer about disease prevention and improving immune response
}

\author{
Mul, M.* \\ Van Niewold, T., Van Riel, J. \\ Wageningen UR Livestock Research, Lelystad, The Netherlands \\ * PO Box 65, 8200 AB, Lelystad, The Netherlands \\ e-mail: Monique.Mul@wur.nl; fax: +31320293591
}

\begin{abstract}
The ability of pigs to avoid illness can be in囚uenced by pig farmers via management measures which prevent stress and introduction and spread of diseases. A training program consisting of three meetings, was developed to achieve more consciousness at pig farmers about their in囚uence on disease prevention and the immune response of their pigs. We tested the effect of the training program on the average daily gain in weight, feed conversion, the mean percentage of lymphocytes and I-FABP values.

After one year, the farmers of the test group who joined three meetings, indicated that they achieved more insight in the points of action to improve the immune response of their pigs and prevent diseases as a result of the meetings. They also undertook significantly more improvements than farmers from the control group. On average the pigs of the farms in the test group had a better gut health than the pigs of the farms in the control group. The average daily gain in weight and the feed conversion of the pigs were significantly better from farms in the test group compared to the pigs from the farms of the test group, but only during the first three months after the meetings.
\end{abstract}

\section{Introduction}

The ability of pigs to avoid illness is affected by intrinsic factors (e.g. genetics) and by extrinsic factors (housing situation, feed, hygiene, temperatures, handling ). By optimizing the extrinsic factors, less adaptive capacity is required to withstand health challenges, which means that more energy is left for growth and development. Many of the extrinsic factors are management factors, and can be controlled directly or indirectly by farmers (Boersma et al., 2005). A training program should give farmers more insight in their in囚uence on the immune response of the pig and in disease prevention. This newly gained knowledge should also be taken over by the farmers to achieve effect. We tested the effect of a farmers training program on pig health, average daily gain in weight, feed conversion, the mean percentage of lymphocytes and I-FABP values.

\section{Material and Methods}

For one year seventeen pig farmers, the test group, attended a test which consisted of three meetings in which the farmers, together with their veterinarian, achieved knowledge about their possibilities to in囚uence the immune response of the pig and to prevent diseases. Eighteen pig farmers, the control group, did not attend these meetings. The aim for the meetings of the training program was application of management measures for a better immune response of the pigs and to minimize disease introduction into the farm and transfer of disease within the farm. Before the first meeting, researchers visited the farms and filled in a questionnaire together with the farmers, to identify the points of improvement. The first meeting consisted of a) knowledge transfer and b) farmers discussing their farms points of improvement with other farmers at five themes (animal handling, feed and water, climate, pathogen burden/ hygiene/ vaccination, care of sow and piglet) to achieve more insight in the factors to be optimized at their own farm. Hereby, farmers knew the strong points of their farm and the points for improvement. During the second meeting, farmers answered their own formulated questions together with other farmers, veterinarians and pig researchers, to improve their farms. A plan of action was made with set deadlines during the third meeting. Farmers carried out this plan for at least half a year. The three meetings were held every four to six weeks.

Before the first meeting and six months after the third meeting (one year after the first visit to the farm), the percentage of lymphocytes and I-FABP (Intestinal Fatty Acid Binding Protein) was measured in blood taken from 30 fattening pigs of 50 kilogram. The percentages of lymphocytes indicates the disease resistance in general or the state of health at a certain 
moment. I-FABP can be measured in blood when leakage of the intestine is present for example due to stress or changes in feed (Niewold et al., 2004). Average daily gain in weight of the pigs (ADG) and feed conversion ratio (FC) were measured every three months. An evaluation of the training program and the number of improvements taken by the farmer were achieved by means of a questionnaire. The difference on the number of improvements during the test period taken by the farmer was tested with a generalized linear regression model. The difference in increase or decrease of the percentage of lymphocytes and I-FABP between the test and control group was analysed with a linear regression model (Genstat8, 2005). The farms with changes in breeding strategy were excluded from the analyses. The difference in the development of ADG and FC was tested with a regression model.

\section{Results}

After one year, the farmers of the test group indicated that they improved their farm and that they achieved more insight in the points of action to improve the immune response of their pigs and prevent diseases as a result of the training program (figure 1).

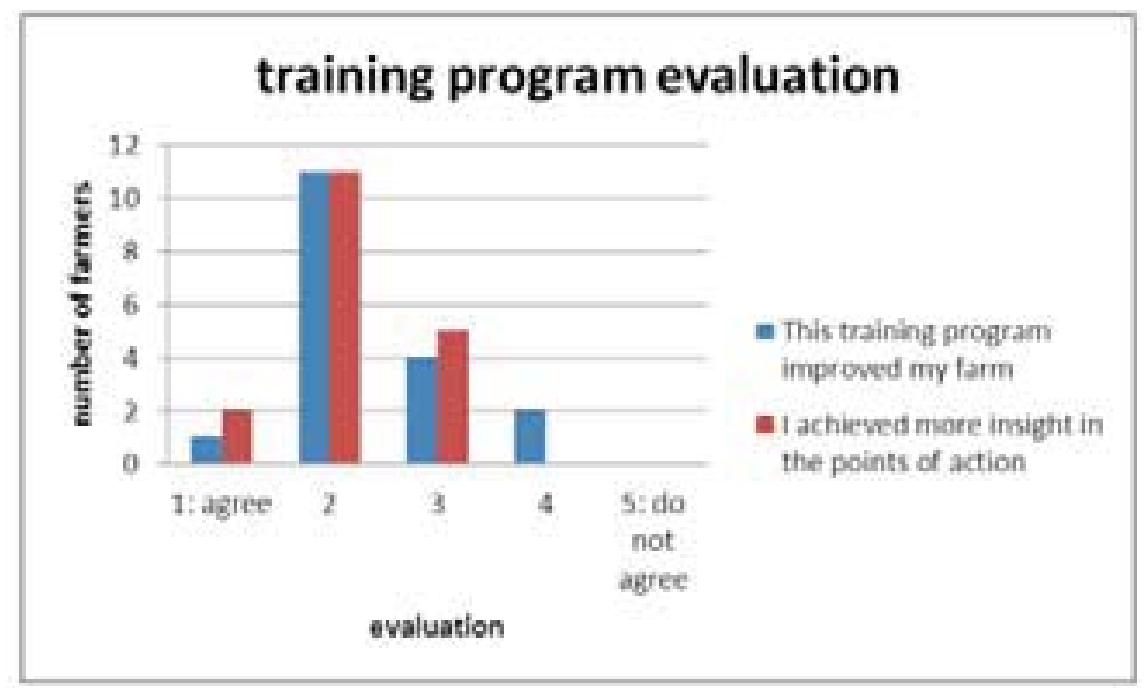

Figure 1 Farm evaluation of the training program

The average number of improvements was significantly higher at farms of the test group (table 1).

Table 1 Average number of improvements per farm and per theme.

\begin{tabular}{lcc}
\hline Theme & Test Group $(\mathrm{n}=16)$ & Control Group $(\mathrm{n}=17)$ \\
\hline $\begin{array}{l}\text { Average number of } \\
\text { improvements per farm }\end{array}$ & 16.4 & $7.4^{*}$ \\
\hline Improvements per farm & & \\
\hline Others (farm size, breed,, ) & 0.5 & 0.3 (n.5.) \\
\hline Pig management & 4.1 & $1.7^{*}$ \\
\hline Feed and water & 3.6 & $1.4^{*}$ \\
\hline Climate & 2.1 & 1.1 (n.s.) \\
\hline $\begin{array}{l}\text { Pathogen burden/ hygiene/ } \\
\text { vaceination }\end{array}$ & 4.4 & $2.2^{\circ}$ \\
\hline Care of sow and piglet & 1.1 & 0.8 (n.s.) \\
\hline
\end{tabular}

\footnotetext{
*: significance: $P<0.01$; n.s. $=$ not significant $(p>0.05)$
}

No significant difference was found between the groups for the mean percentage of lymphocytes and the median of I-FABP value per farm (table 2). However, when analysing the 75\%-quartiel of IFABP, the pigs of the farms in the trail group showed a significant lower increase of I-FABP than the pigs of the farms in the control group $(p<0.05)$.

Table 2 Mean percentage of lymphocytes and Median of the category I-FABP $>40$ of farms in the test group and control group. 


\begin{tabular}{|c|c|c|c|c|}
\hline & \multicolumn{2}{|c|}{ Mean percentage of lymphocytes } & \multicolumn{2}{|c|}{ Median of the eategory I-FABP $>40$} \\
\hline & Test group $(\mathrm{n}=9)$ & $\begin{array}{c}\text { Control group } \\
(n=13)\end{array}$ & Test group $(\mathrm{n}=9)$ & $\begin{array}{l}\text { Control group } \\
(n=13)\end{array}$ \\
\hline $\begin{array}{l}\text { Before first } \\
\text { meeting }\end{array}$ & 61.55 & 60.87 & $110 \%$ & $100 \%$ \\
\hline After one year & 62.02 & 61.73 & $139 \%$ & $173 \%$ \\
\hline $\begin{array}{l}\text { Development } \\
\text { during one year }\end{array}$ & +0.47 & +0.86 & $+28 \%(\bullet)$ & $+73 \%$ \\
\hline
\end{tabular}

*: significance: $p$-value $<0.10(p=0.055)$

The ADG ( $p<0.05)$ and the FC ( $p=0.001)$ were significantly better for the test group compared to the control group, but only during the first three months after the meeting, 4-6 month after the first visit (table 3).

Table 3 Average Daily Gain and Feed Conversion Ratio for the test and control group during four periods of three months.

\begin{tabular}{lccccc}
\hline Period & \multicolumn{2}{c}{ Average daily weight gain $(\mathrm{n}=17)$} & \multicolumn{2}{c}{ Feed conversion ratio $(\mathrm{n}=17)$} \\
\hline & Test group $(\mathrm{n}=9)$ & Control group $(\mathrm{n}=8)$ & Test group (n=9) & Control group $(\mathrm{n}=8)$ \\
\hline $\begin{array}{l}\text { Month 1-3 (after } \\
\text { first farm visit) }\end{array}$ & 0 & 0 & 0 & 0 \\
\hline Month 4-6 & $30.2\left({ }^{*}\right)$ & 0 & $-0.24\left(^{*}\right)$ & 0 \\
\hline Month 7-9 & 14.9 & 0 & -0.18 & 0 \\
\hline Month 10-12 & 0 & & 0 & 0.06 & 0 \\
\hline $\begin{array}{l}\text { Significance } \\
\text { (treatment x period) }\end{array}$ & & $\mathrm{P}=0.18$ & & $\mathrm{P}<0.001$ \\
\hline
\end{tabular}

*: significance: P-value $<0.05$

\section{Discussion}

The meetings, the content and the frequencies were effective and useful. Farmers of the test group applied more management measures than the farmers of the control group, however farmers also changed type of antibiotics used and applied extra vaccination where we advised to find the cause leading to the use of antibiotics. This can be more emphasized during the meetings.

There was no difference between the test group and the control group concerning the percentage of lymphocytes. Possibly, the effects of management measures on pathogen burden can be expected after a longer period than one year. The pigs from farms in the test group showed a lower increase of IFABP values than the pigs from farms in the test group which might indicate a better gut health of the pigs from farms in the test group.

The effect of the knowledge transfer on ADG and FC are only seen in the first 3 months after the last meeting. This can be the effect of the measurements taken just after the first meeting. Emphasize on management during the meeting period possibly resulted in improvement of $A D G$ and $F C$, however after the first three months after the last meeting, habituation and less attention diminished the attention of the farmer and therefore the difference diminished.

\section{Conclusion}

A training program consisting of three meetings, gave farmers more insight in their in囚uence on the immune response of the pig and in disease prevention. In this training program farmers achieved knowledge about their possibilities to n囚uence the immune response of the pig and to prevent introduction and spread of diseases. This awareness resulted in more measures on management to improve their farms, a better average daily gain in weight and a better feed conversion, but only during the first three months after the meeting. No difference was found in the mean percentages of lymphocytes. The I-FABP level of the pigs from the test farms increased less than the I-FABP level of the pigs from the control farms, indicating a better gut health in pigs from the test farms.

\section{References}

BOERSMA W.J.A., MEULEN J. VAN DER AND NIEWOLD T.A., 2005. Porcine Disease and Welfare. In: MarchandForde, J. (Ed.), Welfare of pigs. Kluwer Academic Press, Dordrecht.

NIEWOLD T.A., MEINEN M. AND MEULEN J. VAN DER, 2004. Plasma intestinal fatty acid binding protein (IFABP) concentrations increase following intestinal ischemia in pigs. Research in Veterinary Science, 77, 89-9 1. 